\title{
Traffic Congestion and Intelligent Transport System in a Fast-growing Nigeria City
}

\author{
Umar Obafemi Salisu ${ }^{1}$, Ayobami Ademola Akanmu ${ }^{2}$, Simeon Oluwagbenga Fasina ${ }^{1}$, Sekinat Motunrayo \\ Sanni $^{3}$ \\ ${ }^{1}$ Department of Urban and Regional Planning, Olabisi Onabanjo University, Ago-Iwoye, Nigeria \\ ${ }^{2}$ Department of Urban and Regional Planning, The Oke-Ogun Polytechnic, Saki, Nigeria \\ ${ }^{3}$ Transport and Logistics Limited, Ibadan, Nigeria
}

\begin{abstract}
The dismal performance of the traditional traffic congestion measures and motorist attitudes on Nigeria roads have not only made traffic flow unpredictable and worsening but also worrisome and defiling every measures put-in-place by the Government. To solve these problems, the study assessed traffic congestion and Intelligent Transport System (ITS) in Ibadan, Nigeria. In achieving this, the study examined among others, factors aiding traffic congestion; effectiveness of the existing traffic congestion measures; and the performance and disposition to the use of ITS in the study area. Systematic random sampling was used to administer 386 copies of a questionnaire on commercial motorists, while data collected were analyzed using both descriptive and inferential (Pearson Chi-Square and Fisher's Exact Tests) statistics. Findings revealed that faulty intersections (3.586) and excesses of traffic officers (3.558) were worsening factors aiding traffic congestion in Ibadan city. Meanwhile, electronic traffic signalization (3.558) and law enforcement and regulation (3.499) were rated the most effective existing traffic congestion measures. In other words, real-time traffic signal devices (3.609); automated travel advisory system (3.595) and road congestion pricing devices (3.581) were highly rated and favourably disposed to use ITS. However, the Chi-Square Tests shows that the use Intelligent Transport System is statistically influenced by users' level of education (Sig. value $<0.05$ ). The study concludes that there is a total necessity and willingness to use ITS in the study area. Hence, the study recommends exigent and holistic approach in the provision and enforcement of ITS towards mitigating congestion and other suggestions for improved traffic flow in Nigerian cities including Ibadan.
\end{abstract}

Keywords Congestion, Cities, Ibadan city, Intelligent Transport System ITS, Traffic

JEL R49

\section{Introduction}

The pivotal roles of transportation in ensuring human survival and achieving sustainable development are enormous. Such roles are even recognized by the targets and components embedded in the recently unveiled Sustainable Development Goals of the United Nations in which Nigeria is among the stakeholders. Similarly, Nigeria cities are not exempted from urbanization, territorial expansion and expanded socio-economic growth which requires an efficient transportation system. In this regard, transport operations have been fostering the required spatial interaction in numerous dimensions in the country [22]. Despite the economic and social impact of transportation in all spheres of national life, its influence in the expansion and concomitant shaping of cities are outstanding and uncompromising as human activities continued to increase and spread across diverse spatial locations where places of works are separated from homes and residences.
Cities have been feeling the adverse consequences of traffic congestion since time immemorial which later become worse during industrial revolution period and aggravated since the 1900 s as same forces that draw inhabitants to congregate in large urban areas also lead to intolerable levels of traffic congestion on urban streets. Globally, traffic congestion is rising and indicates a strong global economy battler, while in the same vein reflects the extent at which commuters and drivers waste precious time by sitting in traffic, not to mention the huge environmental impact accrued in the process.

However, traffic congestion, no doubt, is one of the most vexing city problems and cannot be narrowly tackled at the cost of a city's quality of life [29]. It is an indiscriminate global phenomenon that is dramatically impacted by population, economy, infrastructure and the proliferation of rideshare and delivery services. As a result, vehicular traffic congestion is widely viewed as a growing problem in many urban areas because the overall volume of vehicular traffic has continued to grow faster than the overall capacity of the 
transportation system networks [5]. Although, the drastic measure has been put in place by many European counties towards mitigating to the effect of traffic congestion. Significantly, the use of highly functional video surveillance devices and other related intelligent devices have successfully and effectively reduced traffic congestion and incidents along with road networks [27]. Unfortunately, this situation is not so in the Third world countries including Nigeria.

As Nigeria's economy and population continue to grow, the number of vehicles plying the roads and highways continue to increase in volume and intensity, while traffic congestion and complimentary adverse consequences continue to escalate. Also, the counterproductive nature of transportation as denoted by externalities in which traffic congestion is the most nagging issue with far-reaching implications and backwash effects in the society has become a recurring issue $[10,26]$. Traffic congestion is a function of the interacting vehicles and is due to poor speed and flow relationships especially when volumes approach capacity at which both the vehicles going slow and vehicles travelling at high speeds contribute and accounted for accumulated traffic consequently causing delay and congestion [11].

The socio-economic consequences of traffic congestion necessitate persuasive reasons in taking actions before related or associated problems become more difficult to manage. Despite government's significant interventions, particularly through human behavioural control, an improvement on the urban road network and capacity expansion in recent times, accessibility and mobility are being increasingly degraded by growing intra-city traffic delay and congestion especially in major Nigerian cities including Ibadan, Lagos, Benin, Osogbo, Akure, Kano, Kaduna, Port Harcourt, Calabar, Onitsha and even Abuja among others. Interestingly, traffic congestion in these cities has continued to attract several attentions from government, researchers, institutions, professional bodies and scholars in the last 42 years. Significantly, scholars such as $[1,2,4,6,18,23,24$, 25 ] among others have critically assessed urban transport situation in Nigeria and suggested measures for its curtailment in several national academic discourse and publications.

Accordingly, national attention to ever-increasing traffic congestion in Nigeria reached its foremost peak in 1977 when 'Transportation in Nigeria National Development' formed the theme of the National Conference held at the University of Ibadan, Nigeria. The conference re-vibrated the challenges of transportation in Nigeria cities and called for immediate stakeholders' interventions since then.

Despite these laudable efforts, traffic congestion and traffic flow have not only been worsening in Nigeria urban centres and large cities at an alarming rate but also defiling every measure put in place. For instance, the traditional traffic control measures, as well as the introduction of improved congestion control measures like road capacity expansion, construction of overpass and underpass, ring road and traffic signals in addition to the established institutional human frameworks for manual control through the statutory agencies, have not achieved desired results of ensuring a free flow of traffic. This situation appeared to have reached elastic limits considering the worsening situation of efforts in place to redress the dilemma. Precisely, the extent of the persistent traffic congestion in Ibadan city and many other Nigeria cities is now undermining the importance of transportation to residents, communal wealth and national growth in numerous dimensions. Surprisingly, individuals, businesses and even sectors of the society are being adversely affected by this recurring urban mobility dilemma in the city. Therefore, the acute limitation and dismal performance of the existing traffic control measures in arresting the ever-growing traffic congestion in Ibadan and other Nigeria cities underscore the rationale for devising and exploring other alternatives; hence, the need to shift attention to smart transport technologies vis-à-vis Intelligent Transport System ITS and Information and Communication Technology (ICT) tools to ensure efficient traffic flow and service delivery in Nigeria cities.

It is based on these backdrops that this study assessed traffic congestion and intelligent transport system in a fast-growing Nigeria city of Ibadan city since her transport issues are more peculiar and complex than other fast-growing cities in Nigeria and again, the transport network of the city is without functional and degraded intelligent transport devices. To this end, this study explores and established the opportunities derivable in the use of improved ITS and other smart transport initiatives for efficient and sustainable road traffic operations and management in the fast-growing Nigerian cities and equally bridge the academic gap on the topical issue in the sub-Sahara African countries by proffering better measures and policy recommendations that will facilitate timely, safe and smart mobility delivery in Ibadan city and cities with similar transport characteristics and challenges.

In achieving this aim, specific objectives examined were the motorist profile and route characterization in Ibadan city; factors aiding traffic congestion in the study area; effectiveness of the traditional and existing traffic congestion measures in Ibadan city; the performance and disposition of respondents to Intelligent Transport System ITS and Smart Transport Initiatives STI for traffic congestion and flow management in the study area. In other words, this study was structured into five sections for clear and logical understanding. Following the introductory sections were the conceptual clarification and brief literature review. The third section dealt with the research methodology that gave insight into the study area, sampling procedure, method of data collection and techniques of analysis. The last two sections that are section four and five presented the results and discussion of findings as well as the study conclusion and recommendations. 


\section{Conceptual Underpinning and Brief} Literature Review

\subsection{Concept of Smart Transport Initiatives STI}

This study is anchored on the concept of Smart Transport which according to [16] encompasses a range of systems and applications to tackle transportation challenges. The concept is otherwise known as Intelligent Transport System (ITS) which include different modes of transport and traffic management, real-time traveller information, centralized fleet management, road usage charging, smart charging for electric vehicles and vehicle-to-vehicle systems etc. smart transport is based on Information and Communication Technology (ICT) which enables the elements within the transport system to become intelligent by embedding sensors and microchips in these elements. These wireless technologies allow communication between these elements to enhance the performance of the system, reduce congestion and increase road safety. Reference [11] sees Information and Communication Technology ICT as a set of heterogeneous technologies (hardware and software) that allow for electronic communication, data collection and processing in distributed networks as well as electronic guidance and management through sensor technologies. As a result, ITS is a system of layers comprising infrastructures, services on these infrastructures, vehicles moving through the system of infrastructures, and persons and freight moving in these vehicles.

Reference [28] were of the view that ITS covers both Information Technology (IT) and Telecommunications that is useful as traffic management solutions for social innovation; hence, ITS/ICT satisfies requirements such as optimization of investment and innovation to affect society and its production capacity. Similarly, the [7] opines that ITS as a key enabler to achieve public policy objectives, support the design of urban mobility, congestion minimization and offer tailor-made alternative measures so aside from being adapted to a wide variety of urban mobility situations. Therefore, as the core of urban mobility package, Intelligent Transport System (ITS) provides very concrete solutions for traffic flow and travel operations and management, thereby reducing congestion and its resulting negative externalities.

\subsection{Literature Review}

Traffic has always been a common phrase used by an individual in expressing the chaotic vehicular movement experienced in their intra-urban movement and refers to pedestrians or vehicular on the road or the state of ongoing change or the passage thereof in the cities [3]. In this regard, cities have been feeling the adverse consequences of traffic and traffic congestion since time immemorial which later become worse during industrial revolution period and aggravated since the 1900s as same forces that draw inhabitants to congregate in large urban areas also lead to intolerable levels of traffic congestion on urban streets. Globally, traffic congestion is rising and indicates a strong global economy, while in contrary reflects the extent at which drivers' waste time by sitting in traffic, not to mention the huge environmental impact accrued in the process. Traffic congestion, no doubt, is one of the most vexing city problems and cannot be narrowly tackled at the cost of a city's quality of life [29]. It is an indiscriminate global phenomenon that is dramatically impacted by population, economy, infrastructure and the proliferation of rideshare and delivery services. As a result, vehicular traffic congestion is widely viewed as a growing problem in many urban areas because the overall volume of vehicular traffic has continued to grow faster than the overall capacity of the transportation system [5].

Congestion is an unavoidable consequence of scarce transport facilities such as road space, parking area, road signals and effective traffic management. As a result, urban congestion mainly concerns two domains of circulation, passengers and freight which share the same infrastructure. By this, the condition of traffic congestion on road networks occurs as a result of excessive use of road infrastructure beyond capacity, and it is characterized by slower speeds, longer trip hours and increased vehicular queuing. In the opinion of [12], traffic congestion disrupts business activities and reduces productivity level despite being a symbol of growth in an economy since economy grows and increase in real income of household usually lead to a surge in vehicle population thereby contributing to traffic congestion, particularly within cities.

In recent years, and especially since the early 1990s, the increase in road traffic and the demand for transport has caused serious traffic congestion, delays, accidents and environmental problems in large cities. Road traffic jams, according to [13] continue to remain a major problem in most cities around the world, especially in developing regions resulting in massive delays, increased fuel wastage and monetary losses. In Nigeria, and most especially in Lagos, the impact of traffic congestion is palpable to anyone witnessing delay on Lagos roadways as an estimated 8 million people travel to work via public transportation each day on the 9,100 roads and expressways available in Lagos [14]. With more than 1 million registered vehicles in 2011, there are potentially more than one million trips made during the peak travel periods of the day; this is much more during seasonal festivities such as Easter and Christmas when there is an influx from other parts of the country.

According to [17], reformation and advancement in Information and Communication Technologies have resulted in wider applications all over the world in this century. Therefore, the integration of Intelligent Transport Systems (ITS) through ICT solutions becomes necessary towards achieving a smooth flow of traffic in cities and other metropolitan areas in the country. Reference [25] observes that the acceptance of ITS will significantly help to manage road networks, coordinate traffic and reduce travel times. ICT is a value enhancement strategy for ensuring free traffic flow towards achieving effective traffic management in contemporary settlements across the world. Reference [27] observed that the use of multi-sensor video surveillance systems and other smart transport devices along with road networks in 
European cities significantly help to reduce the emergency, traffic flow and traffic incidents on the relevant section of the roads and equally assist the work of traffic inspector in violation measures. With this, ITS and ICT traffic management system is critical in managing traffic flow in contemporary African societies; hence, the rationale for this study in embracing the use of ITS as smart transport initiatives towards achieving improved traffic flow, reduced congestion, coordinate travel time and behaviour and improved traffic safety in Ibadan city, Nigeria.

\section{Material and Methods}

\subsection{Scope of the Study}

Importantly, on the locational score, the study was limited to Ibadan city since the city is the biggest in sub-Sahara African and characterized with pressing mobility and accessibility dilemma, alarming congestion, unorganized public transport system, inconsistency transport policies and lack of functional smart transport technologies along major road network corridors despite its socio-economic and location advantages ahead of other cities in Nigeria. On the subject scope, the study was limited to the commercial motorists as the only group of respondents and equally a major group of users who regularly uses and assigned to the major routes within the city for daily urban public commuting services in the fast-growing city of Ibadan.

\subsection{The Geography of Ibadan City}

Ibadan city, according to [20] is recognized as a nodal settlement because of its transportation network advantage facilitated by its aged long political, administrative and commercial functions in addition to her suitably geographical location being enjoyed till date. The principal routes in Ibadan city are Lagos/Ibadan highway to the South, Ibadan/Oyo/Ilorin highway to the North; Ibadan/Ife/Ilesha highway to the East and Ibadan/Ijebu/Abeokuta highway to the West. Several intra-city routes and corridors which transverse Ibadan provide both mobility and accessibility for all land use and residents.

Ibadan city is geographically located in south-western Nigeria and the south-eastern part of 0yo state, approximately on longitude $3^{0} 55^{1}$ East of the Greenwich Meridian and Latitude $7^{0} 23^{1}$ North of the Equator [9]. The approximate land area of Ibadan city (i.e. 11 Local Government Areas-LGAs) is $55 \mathrm{~km}$ by $70 \mathrm{~km}$ totalling 3,850 square kilometres or 385,000 hectares, which is about $14.13 \%$ of the total landmass of Oyo State (27, 249 square km). According to [8], Ibadan emerged around 1830 at a time of political turmoil in Yoruba land and first served as a war camp before it grew to a full-fledged town, and later to attain the status of a city-state with the largest population size in Yoruba land in a gasping manner. According to [19], Ibadan had developed over a large area approximated to 103.8 square $\mathrm{km}$ in 1970 , while in 1982 it was estimated that the city had covered an area of about 130.5 square $\mathrm{Km}$. The landscape of Ibadan is dotted with hills, river valleys and plains with drainage network of rivers and streams. Meanwhile, Ibadan city is inhabited by $3,464,000$ in 2019 based on the projected population using the National Population Commission of 2006. Public transport services are provided mainly by the private sector, notably by taxis, buses and motorcycles [26]. These services are, however, supplemented by the state government-owned Pacesetter Transport Service whose vehicles operate more intercity transportation than intra-city services.

\subsection{Methods}

The research methods in this study includes the research design, sources of data used, methods of data collection, sampling procedure, population and sample size, method of data presentation and analysis as well as the postulated research hypothesis. This study used a mixed methods of cross-sectional research design that combined both qualitative and quantitative approaches in achieving research objectives. The qualitative approach enables researcher in getting in-depth information on the topical issues, while quantitative approach helped in obtaining and analyzing numerical data from the sample. Meanwhile, both primary and secondary sources of data were employed for this study. The primary data was majorly through questionnaire administration and complemented by field observation of traffic situations and traffic control devices identified along screening routes in the study area. This means of data collection provided the first-hand and insight into the research questions and objectives were addressed. Furthermore, the secondary data was through consultation of relevant and related literature on topical issues in a global manner. However, deductions and inferences were objectively and subjectively made based on the two data sources.

The study was limited to only the registered commercial motorists as a major group of users who are assigned and regularly uses major routes within the city for daily urban commuting services. Meanwhile, systematic random sampling was used to administer 386 copies of a questionnaire on the registered commercial motorists along seven randomly screened route corridors in Ibadan city. The route corridors are Iwo road-Challenge road; Bere/Oje road-Iwo road; Bere/Yemetu road-University of Ibadan road; University of Ibadan road-Sango/Dugbe road; Challenge road-Ring Road/Dugbe; Dugbe road-Apata road, and Dugbe road-Eleyele road. The sample size (386) was extracted from the 2019 registered commercial motorist of ten thousand and eight hundred motorists $(10,800)$ sourced from the National Union of Road Transport Workers (NURTW) in the study area using Taro Yamane sample size formula: $\mathrm{n}=\mathrm{N} / 1+\mathrm{N}^{*}(\mathrm{e}) 2$

Where $\mathrm{n}=$ the sample size, $\mathrm{N}=$ the population size and $\mathrm{e}=$ the acceptable sampling error. 
However, out of the 386 administered copies of the questionnaire, a total of 353 copies equivalent of $91.5 \%$ were retrieved from the field and used for analysis. Meanwhile, data collection were made possible with the support of research assistants and traffic control officers. Furthermore, collected data were analyzed using both descriptive (percentage distribution table and Summation of Mean Weighted Value MWV) and inferential (Pearson Chi-Square Test and Fisher's Exact Test) statistics techniques with the use of Statistical Package for Social Sciences SPSS IBM version 21.

\subsection{Research Hypothesis}

The postulated hypothesis was tested to establish the influence of respondents' socio-economic status (educational level) on the use Intelligent Transport System ITS devices in the study area. The research hypothesis was tested using both Pearson Chi-Square Test and Fisher's Exact Test and thus, presented in the alternate form as:

\section{$H_{1}$ : The use ITS devices is a function of users' level of education}

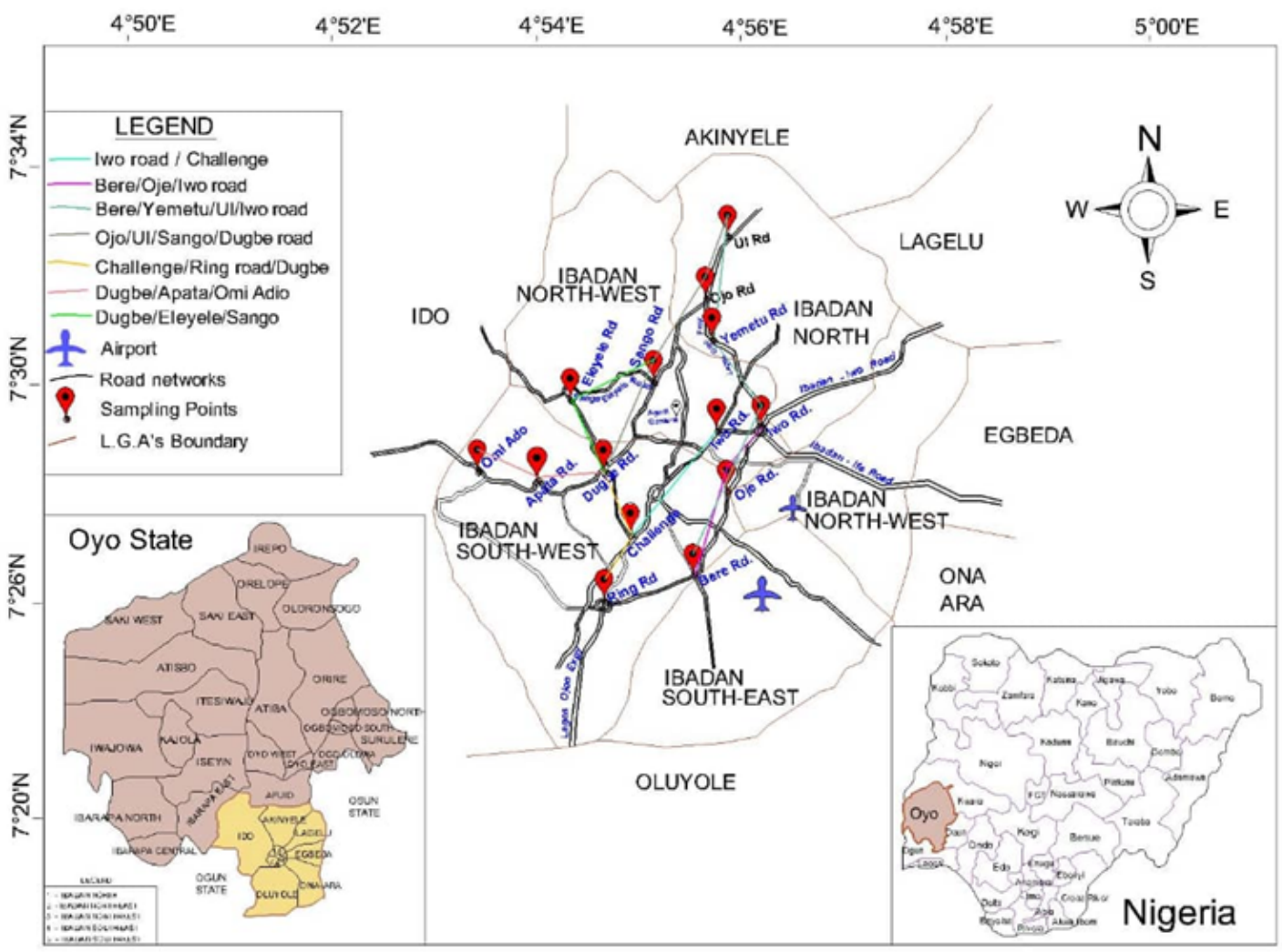

Figure 1. Map of Ibadan city in Oyo State, Nigeria showing the route corridors and sampling points

\section{Results and Discussion}

The results of the analysis of data obtained from the administered questionnaire are presented in this section. Precisely, it consists of the findings on motorist profile and route characterization, factors aiding traffic congestion in Ibadan metropolis, appropriateness and effectiveness of existing traffic congestion measures, motorists' disposition to smart transport technologies as well as their readiness towards smart transport technology initiatives capable of producing desired results of a free flow of traffic in the study area. The unending traffic congestion in Ibadan is being facilitated by different factors which this study was able to establish and suggested measures towards achieving meaningful reduction if not total eradication.
The analysis was done on a 4-point Likert scale in which the gradation is ranked as VL-Very low; L- low; H- High and $\mathrm{VH}-$ Very High in Table 6, while in Table 7, the indices are I: Inappropriate; SI: Slightly Inappropriate, SA: Slightly Appropriate and A: Appropriate. Table 8 has the gradation which consists of SD: Strongly Disagree, D: Disagree; U: undecided; A; Agree and SA: Strongly agree of which the stated graduation was coded as 1, 2, 3, and 4 respectively. The index for each variable is arrived at by dividing the Summation of Mean Weighted Value (MWV) by the total number of responses. According to [10], MWV for a variable is obtained through the addition of the product of the number of responses to each aspect and the respective weight 
value attached to each rating. This is expressed quantitatively as thus:

Where:

$$
\mathrm{MWV}=\mathrm{\Sigma}_{\mathbf{l}=1}^{\mathrm{F}} X_{l} \mathrm{E}_{l}
$$

MWV $=$ Summation of Mean Weighted Value,

$\mathrm{Xi}=$ number of respondents to rating $\mathrm{i}$

$\mathrm{Yi}=$ the weight assigned a value $(\mathrm{i}=1,2,3,4,5)$

With this, the higher the Relative Index Mean Value (RIM), the higher the level of effectiveness for the variable under consideration is and this is expressed quantitatively:

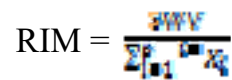

\subsection{Motorist Profile and Route Characterization}

The presentation of findings in Table 1 was done using the simple percentage of the distribution. It is interesting to note that out of the 353 sampled motorists, $94.7 \%$ are male while $5.3 \%$ are female, implying that majority of the commercial motorist in the study area are male with a huge percentage as compared to their female counterpart. On the age group of respondents, findings revealed that majority $(42.7 \%)$ of respondents are between age 25- 35 years, $18 \%$ is less than 25 years of age, $26 \%$ are $36-45$ years, while the least percentage $(13.3 \%)$ are respondents above 45 years. This shows that most of the drivers are in their active age with the strength required to meet up the physically demanding jobs available as a source of income or form of employment. Also, the majority (about $70 \%$ ) of the sampled motorists are married and are expected to display a high sense of responsibility.

Evidence from Table 1 also shows that the majority (about $60 \%$ ) of motorists' are holders of primary/secondary school certificate holders, while National Diploma holders or its equivalent, Degree certificate holders, and respondents with no formal education accounted for $12.7 \%, 24 \%$ and $6.6 \%$ respectively. Concerning the average daily income of motorists, only $5.8 \%$ earns below $\# 2,000$, while $12.6 \%$ earns between $\# 2,000$ and $\# 4,000$. Also, more than a quarter (39.9\%) earns between $\# 4,000$ and $\# 6,000$, while the remaining $41.7 \%$ earns more than $\# 6,000$ Nigerian Naira after the deduction of daily running cost. Accordingly, the average daily income of motorists are not the same but vary on the extent and patronage recorded as well as other factors including vehicle ownership, excesses of trade unions and traffic officers.

In other words, the ownership of vehicles being used for commercial transportation operations in the study area varies. Accordingly, Table 1 also showed that $27.2 \%$ of the respondents indicated self-owned and drive vehicle, $12.6 \%$ indicated friends owned and drive vehicle, while $22.3 \%$ indicated the union's owned vehicle. The remaining $33.0 \%$ and $4.9 \%$ accounts for a franchise and cooperative vehicles respectively. However, it is worthy to note that as big as the metropolitan area is, there is absolutely no government support and a subsidized vehicle in use for commercial trans- portation operation the study area. Meanwhile, the conventional public transportation scheme in the city is in a state of near collapse. Consequently, this gap left the city public transportation operation in a state of obfuscation.

Table 1. Motorists Profile

\begin{tabular}{|l|l|l|l|l|l|}
\hline Gender & Freq. & $\mathbf{\%}$ & Educational Level & Freq. & $\mathbf{\%}$ \\
\hline Male & 334 & 94.6 & No Formal Education & 85 & 24.0 \\
\hline Female & 19 & 5.4 & Primary/Secondary & 184 & 52.0 \\
\hline Total & 353 & 100 & National Diploma & 61 & 17.4 \\
\hline Age & Freq. & $\mathbf{\%}$ & Tertiary Degree & 23 & 6.6 \\
\hline$<25$ years & 64 & 18.0 & Total & 353 & 100 \\
\hline 25-35 years & 150 & 42.7 & Average daily income & Freq. & $\mathbf{\%}$ \\
\hline $36-45$ years & 92 & 26.0 & Below \#2,000 & 20 & 5.8 \\
\hline Above 60 years & 47 & 13.3 & \#2,000 - \#4,000 & 45 & 12.6 \\
\hline Total & 353 & 100 & $\# 4,001-\# 6,000$ & 141 & 39.9 \\
\hline Vehicle Own- & Freq. & $\mathbf{\%}$ & Above 6,000 & 147 & 41.7 \\
\hline ership & 353 & $\mathbf{1 0 0}$ & Widow/ widower & 5 & 1.4 \\
\hline $\begin{array}{l}\text { Self-owned and } \\
\text { drive }\end{array}$ & 96 & 27.1 & Total & Freq. & $\mathbf{\%}$ \\
\hline Friend's owned \\
and drive
\end{tabular}

Authors' Fieldwork, 2019

The investigation conducted showed a clear variation in the motorists' patronage along the seven classified routes used for this survey. Based on the data presented in Table 2, Route 1, Route 4 and Route 5 are mostly plied by the commercial motorists $30.9 \%, 24.4 \%$ and $19.5 \%$ respectively, while less than $10 \%$ of the sampled motorists do ply Route 2, Route 3 , Route 6 and Route 7 on daily basis. Accordingly, the study revealed that the seven screened routes are prominent principal routes in Ibadan metropolis attracting a significant proportion of motorists and commuters daily. However, based on field observation, these routes are without intelligent traffic devices and electronic traffic calming and monitoring devices despite the high volume of traffic plying them on daily basis. 
Table 2. Route choice by motorists

\begin{tabular}{|l|l|l|}
\hline Routes & Freq. & Per cent \\
\hline Route 1: Iwo road/Challenge & 109 & 30.9 \\
\hline Route 2: Beere/Oje/Iwo road & 25 & 7.1 \\
\hline Route 3: Beere/Yemetu/UI/Ojo & 33 & 9.3 \\
\hline Route 4: Ojo/UI/Sango/Dugbe & 86 & 24.4 \\
\hline Route 5: Challenge/Ring road/Dugbe & 69 & 19.5 \\
\hline Route 6: Dugbe/Apata/Omi Adio & 20 & 5.7 \\
\hline Route 7: Dugbe/Eleyele/Sango & 11 & 3.1 \\
\hline Total & 353 & 100 \\
\hline
\end{tabular}

Authors' Fieldwork, 2019

Also, different reasons are given for the choice of routes frequently plied by sampled motorists. As shown in Table 3, $24.3 \%$ plies the choice route for personal safety reason, while more than half $(53.4 \%)$ considered patronage volume that is, because of the high volume of passengers commuting along the corridor as the reason for their route choice. Also, only $2.9 \%$ complied with government allocated routes, while the remaining $19.4 \%$ has to comply with the vehicle's owner in plying routes for commercial operations. This shows that route control by government and transport administrator is less effective as commercial motorists considered many other things before servicing route that interests them. Ironically, this observed dilemma no doubt has a huge effect on the trip distribution pattern in the city as some routes are underutilized while some are over-utilized leading to congestion along these corridors.

Table 3. Reason for the route choice

\begin{tabular}{|l|l|l|}
\hline Reasons & Freq. & Per cent \\
\hline Personal safety & 86 & 24.3 \\
\hline Government allocation & 10 & 2.9 \\
\hline Vehicle's owner directive & 68 & 19.4 \\
\hline Patronage volume & 189 & 53.4 \\
\hline Total & 353 & 100 \\
\hline
\end{tabular}

Authors' Fieldwork, 2019

There are four categories of vehicles being used for commercial operations along the seven screened routes in the study area and the most-used are shown in Table 4 . In this regard, $29.1 \%$ are car/taxi, $35.9 \%$ are motorcycle, $20.4 \%$ are tricycle, while the remaining $14.6 \%$ are minibus. This shows that the mass transit system is not in operation along the study route. Hence, the domineering of the routes by para transit modes with low carrying capacity with a disorganized way of operations and illogical parking system.
Table 4. Type of vehicle

\begin{tabular}{|l|l|l|}
\hline Types & Freq. & Per cent \\
\hline Car/taxi & 103 & 29.1 \\
\hline Motorcycle & 127 & 35.9 \\
\hline Tricycle & 72 & 20.4 \\
\hline Minibus & 52 & 14.6 \\
\hline Total & 353 & 100 \\
\hline \multicolumn{2}{|c|}{ Authors' Fieldwork, 2019}
\end{tabular}

The period of operations of the motorists is classified into three as presented in Table 5. Accordingly, only $46.6 \%$ do operate within the morning period of 6 am-11:59 am only, while a quarter $(25.2 \%)$ operates within the afternoon period of noon $-6 \mathrm{pm}$ only and the remaining $28.2 \%$ operates within the evening period only. However, this data technically revealed that a vehicle may probably be operated by three different drivers in a day due to the poor socio-economic status of the city as well as the huge demand of urban mobility needs.

Table 5. Periods of operation

\begin{tabular}{|l|l|l|}
\hline Period & Freq. & Per cent \\
\hline Morning (6-12noon) & 164 & 46.6 \\
\hline Afternoon (12-6 pm) & 89 & 25.2 \\
\hline Evening (6-11 pm) & 100 & 28.2 \\
\hline Total & 353 & 100.0 \\
\hline
\end{tabular}

\subsection{Factors Aiding Traffic Congestion in Ibadan}

Based on this estimation, it is observed in Table 6 that 3.281 is the Mean Weighted Value MWV of the identified factors aiding traffic congestion in the study area. The factors are broadly categorized into three namely worsening, moderate and below average. With this, the worsening factors aiding traffic congestion has Relative Index Mean Value RIM that is greatly higher than the Mean Weighted Value MWV, while the moderate factors are observed with a slightly higher value than the MWV and factors with a value below the MWV are factors that less contributory to the traffic congestion within the metropolis. However, faulty junction and the intersection has the highest potent value of 3.586 exceeding the MWV and is closely followed by unprofessional conducts and excesses of traffic officers (3.558) (see Figure $2 \& 3$ ). Next to that are the unguided activities of commercial motorcycle operators (3.530); persistent queue indiscipline of motorists (3.524); deplorable road conditions (3.490); and poorly design speed breaker and bumps (3.402). Also, trucking operators' exuberance/intolerance (3.343); poor routes connectivity and carriage capacity (3.275) (see Figure 2 ); street trading (3.265) and On-street parking/ parking difficulties (3.265) are moderately aiding factors of traffic congestion (see Figure 2), while poor interchange design and capacity (3.303), traffic crashes/incidents (3.006), activities of tricycle operations (2.992) and road encroachment (2.909), 
as well as the activities of the rickety vehicles (2.909), are less impactful factors aiding traffic congestion along the selected corridors in Ibadan metropolitan area of Oyo State, Nigeria. Meanwhile, it is worthy to note that these factors are not just aiding traffic congestion but also contributing to the unpre- dictable travel time which relatively affecting the socio-economic development as well as sustainable spatial interaction in the city.

Table 6: Factors aiding traffic congestion in Ibadan

\begin{tabular}{|c|c|c|c|c|c|c|c|c|c|}
\hline $\mathbf{S} / \mathbf{N}$ & Factors & VH-4 & H-3 & L-2 & VL-1 & TWV & RIV & MWV & RK \\
\hline 1 & Traffic crashes/incidents & 400 & 540 & 96 & 25 & 1061 & 3.006 & \multirow{15}{*}{3.281} & 12 \\
\hline 2 & Faulty junction/ intersection & 920 & 300 & 46 & 0 & 1266 & 3.586 & & 1 \\
\hline 3 & Excesses of Traffic officers & 940 & 270 & 36 & 10 & 1256 & 3.558 & & 2 \\
\hline 4 & On-street parking/ parking difficulties & 788 & 285 & 56 & 33 & 1162 & 3.292 & & 9.5 \\
\hline 5 & Poor routes connectivity and carriage capacity & 740 & 360 & 36 & 30 & 1166 & 3.303 & & 8 \\
\hline 6 & Activities of motorcycles operators & 940 & 240 & 56 & 10 & 1246 & 3.530 & & 3 \\
\hline 7 & Street trading & 788 & 285 & 56 & 33 & 1162 & 3.292 & & 9.5 \\
\hline 8 & Queue indiscipline & 940 & 234 & 60 & 10 & 1244 & 3.524 & & 4 \\
\hline 9 & Trucking operators' exuberance/intolerance & 788 & 300 & 72 & 20 & 1180 & 3.343 & & 7 \\
\hline 10 & Activities of tricycles operators & 380 & 540 & 116 & 20 & 1056 & 2.992 & & 13 \\
\hline 11 & Deplorable roads & 868 & 285 & 76 & 3 & 1232 & 3.490 & & 5 \\
\hline 12 & Poor interchange design and capacity & 420 & 600 & 36 & 30 & 1086 & 3.076 & & 11 \\
\hline 13 & Speed breakers/ bumps & 820 & 300 & 66 & 15 & 1201 & 3.402 & & 6 \\
\hline 14 & Road encroachment & 308 & 570 & 126 & 23 & 1027 & 2.909 & & 14.5 \\
\hline 15 & Activities of rickety vehicles & 308 & 570 & 126 & 23 & 1027 & 2.909 & & 14.5 \\
\hline
\end{tabular}

Authors' Fieldwork, 2019

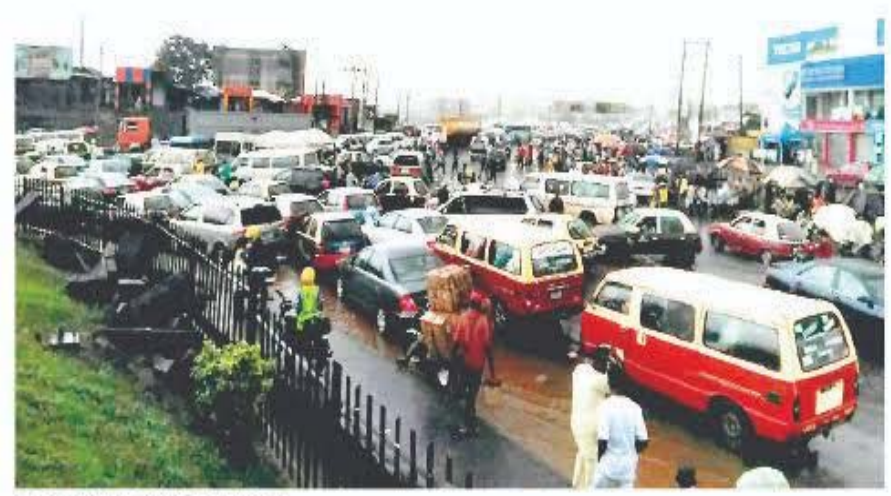

A section of Iwo Road.

Figure 2. A section of Iwo road with faulty intersections and unprofessional conducts of traffic officers

\subsection{Effectiveness of existing traffic congestion measures in Ibadan}

Furthermore, the analysis of the appropriateness of eleven (11) existing traffic congestion measures in Ibadan was presented in Table 7. Findings revealed 3.018 has the Mean Weighted Value MWV. Accordingly, the congestion

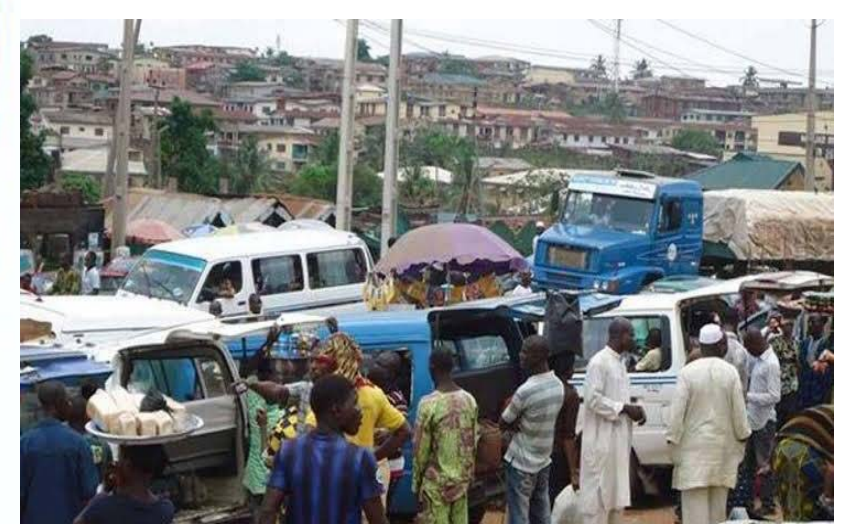

Figure 3. A section of Beere/Yemetu-UI/Ojo road showing unguided packing activities and road encroachment

measures such as electronic traffic signalization with Relative Index Mean Value RIM of 3.558 was observed to be the first rated existing measure that greatly impacts traffic congestion minimization in the study area despite the poor condition of most of the installed related devices. Next to this are the law enforcement and regulation (3.499); road expansion/ dualisation (3.431); public enlightenment (3.292); arterial road maintenance (3.139); road channelization (3.076); and construction of overhead bridges and flyovers (3.037) which are rated second, third, fourth, fifth, sixth and seventh weighted factors respectively and are observed to be appro- 
priate reduction measures for traffic congestion in the city. Nevertheless, underpass (2.983), increased manual traffic control measures (2.890), the introduction of mass transport operation (2.159) and increased construction of speed breaker/ bumps (2.136) are seen as grossly ineffective.
Hence, their ineffectiveness and unsuitably still applied to the curtailment of worsening traffic congestion in the modern city of Ibadan.

Table 7. Effectiveness of existing traffic congestion measures in Ibadan

\begin{tabular}{|c|c|c|c|c|c|c|c|c|c|}
\hline $\mathbf{S} / \mathbf{N}$ & Measure & A-4 & SA-3 & SI-2 & I-1 & TWV & RIM & MWV & RK \\
\hline 1 & Electronic traffic signalization & 920 & 270 & 66 & 0 & 1256 & 3.558 & \multirow{11}{*}{3.018} & 1 \\
\hline 2 & Road expansion/ dualisation & 860 & 285 & 46 & 20 & 1211 & 3.431 & & 3 \\
\hline 3 & Increased speed breaker/ bump & 84 & 225 & 376 & 69 & 754 & 2.136 & & 11 \\
\hline 4 & Road channelization & 400 & 570 & 106 & 10 & 1086 & 3.076 & & 6 \\
\hline 5 & Public enlightenment & 788 & 285 & 56 & 33 & 1162 & 3.292 & & 4 \\
\hline 6 & Law enforcement/ regulation & 880 & 276 & 76 & 3 & 1235 & 3.499 & & 2 \\
\hline 7 & Underpass & 320 & 570 & 160 & 3 & 1053 & 2.983 & & 8 \\
\hline 8 & Arterial road maintenance & 420 & 576 & 112 & 0 & 1108 & 3.139 & & 5 \\
\hline 9 & Increased manual control measures & 280 & 546 & 186 & 8 & 1020 & 2.890 & & 9 \\
\hline 10 & Construction of overhead bridges and flyovers & 424 & 540 & 82 & 26 & 1072 & 3.037 & & 7 \\
\hline 11 & Mass transport operation & 88 & 225 & 386 & 63 & 762 & 2.159 & & 10 \\
\hline
\end{tabular}

Authors' Fieldwork, 2019

\subsection{Intelligent Transport System ITS for Traffic Con- gestion Management}

With the ineffectiveness of the traditional traffic management system and existing traffic congestion measures such as the construction of flyovers, road channelization, one-way system, traffic signals, underpass, speed breaker and relocation of neighbourhood market away from roadways in enhancing persistent traffic congestion in the city, the need for a paradigm shift in these common approaches smart transportation initiatives become crucial. Hence, the adoption of modern smart traffic control measures in the city is inevitable. As a result, Table 8 presents the analysis of the disposition of respondents to the deployment Intelligent Transport System ITS for traffic congestion and flow management in the metropolitan city of Ibadan, Nigeria. The result of the analysis produced Mean Weighted Value estimated at 3.261. Accordingly, respondents strongly agree and favourably disposed to the use of real-time traffic signal devices which has highest Relative Index Mean Value RIM of 3.609 and this is strongly followed by automated travel advisory system (TAS) devices (3.595). Also, the use of automated road congestion pricing devices (3.581); intelligent traffic information devices (3.567); video surveillance sensors /CCTV (3.501); GPS based automated vehicle locators (3.343); intelligent traffic management centre (3.314) are also relatively disposed to use by respondents considering their rela- tive index mean value greater than the Mean Weighted Value of 3.261 unlike other devices that scored below the MWV indicating less disposed devices including automated travel speed and time locator, automated parking system, e-ticketing and automated fare collection devices etc.

Like Reference [20, 21, 24] observed, most congested intra-city routes in Ibadan city include University of Ibadan-Dugbe Route, Dugbe-Apata Route, Olomi/Odinjo/Beere road, Challenge/Podo road, Challenge/Molete/Bere road, Inalende/Oritamerin route, Lagos/Ibadan Tollgate, Iwo road junction, Dugbe/Oke-Ado/Molete route and Challenge-Molete-Beere route, Mokola-UCH/Total Garden-Gate route, Beere-Oje-Iwo road, Beere-Total garden secretariat-U.I. road, Sango-Eleyele road, Eleyele-Dugbe road, Eleyele-Ologuneru road, Apete-Ijokodo-Sango road, Ojo/U.I.-Mokola-Dugbe road and Apata-Dugbe road etc. These routes are congested with long hours delay particularly during the morning, afternoon and evening peaks of the week coupled with longer transit time which sometimes led to terrific and unpredictable traffic situations during weekdays and weekend rush. Meanwhile, it is crystal clear that most of these routes lacks functional Intelligent Transport System. The installed ITS devices including automated traffic calming devices are totally in degraded state (Figure 1). This perhaps is a contributing factor causing the unwanted traffic situation within the observed city. 
Table 8. Smart transport technologies

\begin{tabular}{|c|c|c|c|c|c|c|c|c|c|}
\hline $\mathbf{S} / \mathbf{N}$ & Technology & SA-4 & A-3 & D-2 & SD-1 & TWV & RIM & MWV & RK \\
\hline 1 & Automated travel advisory system (TAS) devices & 920 & 324 & 20 & 5 & 1269 & 3.595 & \multirow{13}{*}{3.261} & 2 \\
\hline 2 & Video surveillance sensors /CCTV & 860 & 300 & 76 & 0 & 1236 & 3.501 & & 5 \\
\hline 3 & Automated vehicle weight and type detector & 280 & 564 & 154 & 18 & 1016 & 2.878 & & 13 \\
\hline 4 & Traffic calming devices & 260 & 570 & 180 & 8 & 1018 & 2.884 & & 12 \\
\hline 5 & GPS based automated vehicle locators & 768 & 309 & 90 & 13 & 1180 & 3.343 & & 6 \\
\hline 6 & Intelligent traffic information devices & 900 & 309 & 50 & 0 & 1259 & 3.567 & & 4 \\
\hline 7 & E-ticketing and automated fare collection devices & 280 & 600 & 140 & 13 & 1033 & 2.926 & & 11 \\
\hline 8 & Electric-powered vehicles & 300 & 594 & 154 & 3 & 1051 & 2.977 & & 10 \\
\hline 9 & Automated parking system & 288 & 738 & 70 & 0 & 1096 & 3.105 & & 9 \\
\hline 10 & The intelligent traffic management centre & 768 & 309 & 70 & 23 & 1170 & 3.314 & & 7 \\
\hline 11 & Real-time traffic signal devices & 920 & 324 & 30 & 0 & 1274 & 3.609 & & 1 \\
\hline 12 & Automated road congestion pricing devices & 920 & 324 & 10 & 10 & 1264 & 3.581 & & 3 \\
\hline 13 & Automated travel speed and time locator & 288 & 744 & 66 & 0 & 1098 & 3.110 & & 8 \\
\hline
\end{tabular}

Authors' Fieldwork, 2019

\subsection{Disposition to the Use of Intelligent Transport System ITS and other Smart Transport Technologies STT}

The results of analyzed data on the disposition to the use of ITS devices and other smart transport technologies by motorists are presented in Table 9. Findings show that $18.5 \%$ resolved that real-time traffic signal devices are not necessary, while the majority $(61.5 \%)$ expressed its necessity and willingness to use, and $13.2 \%$ indicated necessary but unwilling to use, and the remaining $6.8 \%$ was indifference. On the automated traffic calming devices, $15.5 \%$ noted it as unnecessary, the majority (42.8\%) indicated necessary and willing to use, while 9.7 equally support its necessity but unwilling to use and the remaining $32.0 \%$ is indifference to automated traffic calming devices. Likewise, $18.4 \%$ resolved that electronic road/ congestion pricing devices as unnecessary in the city, the majority $(50.5 \%)$ see it as necessary and willing to use, while $6.8 \%$ also expressed its necessity but unwilling to use and the remaining $24.3 \%$ were indifferent in the disposition to the use of electronic road pricing devices as a ITS devices in the study area. Concerning electronic traffic monitoring and surveillance devices (sensor cameras /CCTV), the majority (41.8\%) find it necessary and willing use the devices along the routes, $33.0 \%$ of the respondents noted the devices are unnecessary along the traffic corridors, $5.8 \%$ noted necessary but unwilling to use or obey if install along the route corridors, while $19.4 \%$ of the respondents were indifferent.

Table 9 also shows that $27.9 \%$ viewed automated travel advisory system (ATAS) as unnecessary, the majority (49.8\%) indicated that incident detection and management devices are necessary and willing to use it, while $9.7 \%$ claimed it as necessary but unwilling to use and the remaining $12.6 \%$ were indifferent. On the electric-powered vehicles, majority $55.3 \%$ resolved that the electronic parking system is unnecessary, $31.1 \%$ see it as necessary and willing to use, while $10.7 \%$ see it as necessary but unwilling to use and the remaining $2.9 \%$ were indifferent. Also, analyzed data on automated parking system revealed that $18.4 \%$ see it as unnecessary, the majority $(50.5 \%)$ view it as necessary and willing to use, while $6.8 \%$ claimed it as necessary but unwilling to use and the remaining $24.3 \%$ were indifferent. Findings on GPS based automated vehicle locators revealed that $9.7 \%$ view it as unnecessary, $54.0 \%$ view it as necessary and willing to use, while $18.8 \%$ also noted it necessary but unwilling to use and the remaining $17.5 \%$ were indifferent. More so, the majority $(50 \%)$ of respondents resolved that intelligent traffic management centre is necessary and willing to use, $27.9 \%$ noted it is not necessary, $9.7 \%$ noted necessary but not willing to use, while $12.6 \%$ were indifferent. Similarly, data on intelligent traffic information devices shows that majority over $60 \%$ of respondents found these related devices necessary and willing to use, $18.5 \%$ noted they are not necessary, $13.2 \%$ noted necessary but not willing to use, while $6.8 \%$ were indifferent. In the same vein, the majority $(54 \%)$ of the respondents observed that it is necessary and willing to use automated travel speed and time locator along the transit routes, $9.7 \%$ noted not necessary, $18.8 \%$ respondents noted necessary but not willing to use, while $17.5 \%$ respondents were indifferent. In other words, data on automated vehicle weight and type detector show that majority over $50 \%$ found it not unnecessary along transit routes, $31.1 \%$ found it necessary and willing to use, $10.7 \%$ found it necessary but unwilling to use while less than $3 \%$ respondents were indifferent. In the same vein, the majority (about $40 \%$ ) of the respondents observed that the e-ticketing and automated fare collection system is unnecessary, about $30 \%$ noted necessary and willing to use, $20.4 \%$ found it necessary but unwilling to use, while $14.6 \%$ of the respondents were indifferent. 
Table 9: Disposition to Use Improved Intelligent Transport System ITS Devices

\begin{tabular}{|c|c|c|c|c|c|c|c|c|c|c|c|}
\hline \multirow[t]{2}{*}{$\begin{array}{l}\mathbf{S} / \\
\mathbf{N}\end{array}$} & \multirow[t]{2}{*}{ Smart Technologies } & \multicolumn{2}{|c|}{$\begin{array}{l}\text { Not neces- } \\
\text { sary }\end{array}$} & \multicolumn{2}{|c|}{$\begin{array}{l}\text { Necessary } \\
\text { and willing to } \\
\text { use }\end{array}$} & \multicolumn{2}{|c|}{$\begin{array}{l}\text { Necessary but } \\
\text { unwilling to } \\
\text { use }\end{array}$} & \multicolumn{2}{|c|}{ Indifference } & \multirow{2}{*}{$\begin{array}{l}\text { Total } \\
\text { Freq. }\end{array}$} & \multirow[b]{2}{*}{$\%$} \\
\hline & & Freq. & $\%$ & Freq. & $\%$ & Freq. & $\%$ & Freq. & $\%$ & & \\
\hline 1 & Real-time traffic signal devices & 65 & 18.5 & 217 & 61.5 & 47 & 13.2 & 24 & 6.8 & 353 & 100 \\
\hline 2 & Automated traffic calming devices & 55 & 15.5 & 151 & 42.8 & 34 & 9.7 & 113 & 32 & 353 & 100 \\
\hline 3 & Electronic road/congestion pricing devices & 65 & 18.4 & 178 & 50.5 & 24 & 6.8 & 86 & 24.3 & 353 & 100 \\
\hline 4 & Video surveillance sensors /CCTV & 116 & 33 & 148 & 41.8 & 20 & 5.8 & 68 & 19.4 & 353 & 100 \\
\hline 5 & Automated travel advisory system (ATAS) & 98 & 27.9 & 176 & 49.8 & 34 & 9.7 & 44 & 12.6 & 353 & 100 \\
\hline 6 & Electric-powered vehicles & 195 & 55.3 & 110 & 31.1 & 38 & 10.7 & 10 & 2.9 & 353 & 100 \\
\hline 7 & Automated parking system & 65 & 18.4 & 178 & 50.5 & 24 & 6.8 & 86 & 24.3 & 353 & 100 \\
\hline 8 & GPS based automated vehicle locators & 34 & 9.7 & 191 & 54 & 66 & 18.8 & 62 & 17.5 & 353 & 100 \\
\hline 9 & The intelligent traffic management centre & 98 & 27.9 & 176 & 49.8 & 34 & 9.7 & 44 & 12.6 & 353 & 100 \\
\hline 10 & Intelligent traffic information devices & 65 & 18.5 & 217 & 61.5 & 47 & 13.2 & 24 & 6.8 & 353 & 100 \\
\hline 11 & Automated travel speed and time locator & 34 & 9.7 & 191 & 54 & 66 & 18.8 & 62 & 17.5 & 353 & 100 \\
\hline 12 & Automated vehicle weight and type detector & 195 & 55.3 & 110 & 31.1 & 38 & 10.7 & 10 & 2.9 & 353 & 100 \\
\hline 13 & E-ticketing and automated fare collection & 127 & 35.9 & 103 & 29.1 & 72 & 20.4 & 52 & 14.6 & 353 & 100 \\
\hline
\end{tabular}

Authors' Fieldwork, 2019

However, considering the responses received from Table 9 , the majority of the respondents found most of the ITS and other smart transport technologies necessary. Based on these findings, it can be inferred that the motorists are well aware of the general importance and benefits of the smart transport technologies considering the response rate, although the percentage of indifferent in the use of some devices are still high. This perhaps is not unconnected to the various classifications and unawareness of most of the ITS devices in the study area. Meanwhile, it is clear from the findings that majority of the motorist are willing to use the ITS and/or smart transport technologies if installed along the transit routes in the city to minimize the traffic congestion and longer travel time within the city.

\subsection{Hypothesis Testing}

Association between Educational Level and Use of Intelligent Transport System ITS Devices using

\section{Cross-tabulation, Pearson Chi-Square Test and Fish- er's Exact Test}

Further investigations were conducted on the influence of respondents' level of education and the use ITS devices in the study area. Cross-tabulation was used in the descriptive analysis between the categorical variable (education level) and a group of independent variables measured on a dichotomous form (unnecessary/indifferent $=0$ and necessary willing to use and necessary but not will use $=1$ ). Based on the cross-tabulation results shown in Table 10, it can be deduced that respondents with formal education scored a high percentage than those with no formal education across all the observed ITS devices. By implication, respondents with formal education are more informed about the necessity of ITS devices in mitigating increasing traffic congestion and flow in the city of Ibadan and equally involved in the decision to use or not the ITS devices in the study area. However, those with no formal education were less informed and involved in the decision to use or not the ITS devices as most of their scores to each smart tools were less than ten per cent $(20 \%)$.

Nevertheless, the observed statistical relationship between a categorical variable (educational level of respondents) and the distribution of another group of variables (use of ITS devices) through the use of Pearson Chi-Square Test and Fisher's Exact Test were also presented in Table 10. The Pearson Chi-Square Test and Fisher's Exact Test were used to establishing an independency test results on the influence of respondents educational level on the use of ITS devices. Findings show that twelve (12) out of the thirteen (13) examined ITS devices were associated with or influenced by the level of education of the respondents (Table 10). These findings were observed and confirmed to be statistically significant as their calculated significant values for both the Pearson Chi-Square Test and the Fisher's Exact Test were less than the table significant value of 0.05 (Table 10). Hence, the rejection of the null hypothesis (H0), and acceptance of the alternative hypothesis (H1) which states that the use Intelligent Transport System ITS is a function of respondents' level of education. By implication, it can be inferred that the use ITS devices in the study area is being influenced by the level of education of users most especially the motorist. In other words, the real-time traffic signal devices of the examined ITS devices is observed not to be statistically 
significant as its calculated significant values for Pearson Chi-Square Test (0.516) and Fisher's Exact Test (0.509) were far above the table significant value $(0.05)$ see Table 10 . Hence, the use of real-time traffic signal devices is not a function of the level of education of respondents, rather it is conditioned on other factors that include but not limited to the nature and situation of traffic along the route corridors. However, the twelve (12) ITS that are observed to the significant that is influenced by the level of education of respondents includes the use of automated traffic calming devices (0.02); electronic road/congestion pricing devices
(0.03); video surveillance sensors /CCTV (0.04); automated travel advisory system (ATAS) (0.00); electric-powered vehicles (0.00); automated parking system (0.00); GPS based automated vehicle locators (0.00); intelligent traffic management centre $(0.00)$; intelligent traffic information devices (0.00); automated travel speed and time locator (0.00); automated vehicle weight and type detector (0.00); and E-ticketing and automated fare collection $(0.03)$ for both Pearson Chi-Square Test and Fisher's Exact Test.

Table 10. Cross-tabulation and Chi-Square Tests of Educational Level and the Use of ITS Devices

\begin{tabular}{|c|c|c|c|c|c|c|c|c|c|c|}
\hline \multirow[b]{2}{*}{ Technology } & \multirow[b]{2}{*}{ Readiness } & \multicolumn{5}{|c|}{ Educational Level } & \multicolumn{2}{|c|}{ Pearson Chi-Square } & \multicolumn{2}{|c|}{ Fisher's Exact Test } \\
\hline & & $\begin{array}{l}\text { No Formal } \\
\text { Education }\end{array}$ & $\begin{array}{l}\text { Primary/ } \\
\text { Secondary }\end{array}$ & $\begin{array}{l}\text { National } \\
\text { Diploma }\end{array}$ & $\begin{array}{l}\text { Tertiary } \\
\text { Degree }\end{array}$ & Total & Value & Sig. & Value & Sig. \\
\hline \multirow{3}{*}{$\begin{array}{l}\text { Real-time traffic } \\
\text { signal devices }\end{array}$} & Unnecessary & 5.7 & 12.2 & 7.4 & 0.0 & 25.2 & \multirow[t]{3}{*}{2.307} & \multirow[t]{3}{*}{0.516} & \multirow[t]{3}{*}{2.346} & \multirow[t]{3}{*}{0.509} \\
\hline & Necessary & 18.4 & 39.9 & 9.9 & 6.5 & 74.8 & & & & \\
\hline & Total & 24.1 & 52.1 & 17.3 & 6.5 & 100 & & & & \\
\hline \multirow{3}{*}{$\begin{array}{l}\text { Automated traffic } \\
\text { calming devices }\end{array}$} & Unnecessary & 10.2 & 23.8 & 8.5 & 5.1 & 47.6 & \multirow[t]{3}{*}{9.948} & \multirow[t]{3}{*}{0.019} & \multirow[t]{3}{*}{10.030} & \multirow[t]{3}{*}{0.018} \\
\hline & Necessary & 13.9 & 28.3 & 8.8 & 1.4 & 52.4 & & & & \\
\hline & Total & 24.1 & 52.1 & 17.3 & 6.5 & 100 & & & & \\
\hline \multirow{3}{*}{$\begin{array}{l}\text { Electronic } \\
\text { road/congestion } \\
\text { pricing devices }\end{array}$} & Unnecessary & 12.7 & 21.0 & 5.4 & 3.7 & 42.8 & \multirow[t]{3}{*}{9.225} & \multirow[t]{3}{*}{0.026} & \multirow[t]{3}{*}{9.183} & \multirow[t]{3}{*}{0.026} \\
\hline & Necessary & 11.3 & 31.2 & 11.9 & 2.8 & 57.2 & & & & \\
\hline & Total & 24.1 & 52.1 & 17.3 & 6.5 & 100 & & & & \\
\hline \multirow{3}{*}{$\begin{array}{l}\text { Video surveillance } \\
\text { sensors /CCTV }\end{array}$} & Unnecessary & 14.7 & 26.9 & 6.5 & 4.0 & 52.1 & \multirow[t]{3}{*}{8.596} & \multirow[t]{3}{*}{0.035} & \multirow[t]{3}{*}{8.547} & \multirow[t]{3}{*}{0.035} \\
\hline & Necessary & 9.3 & 25.2 & 10.8 & 2.5 & 47.9 & & & & \\
\hline & Total & 24.1 & 52.1 & 17.3 & 6.5 & 100 & & & & \\
\hline \multirow{3}{*}{$\begin{array}{l}\text { Automated travel } \\
\text { advisory system } \\
\text { (ATAS) }\end{array}$} & Unnecessary & 12.2 & 18.4 & 3.4 & 6.2 & 40.2 & \multirow[t]{3}{*}{45.736} & \multirow[t]{3}{*}{0.000} & 48.250 & 0.000 \\
\hline & Necessary & 11.9 & 33.7 & 13.9 & 0.3 & 59.8 & & & & \\
\hline & Total & 24.1 & 52.1 & 17.3 & 6.5 & 100 & & & & \\
\hline Electric-powered & Unnecessary & 9.9 & 34.0 & 13.3 & 0.8 & 58.1 & 41.999 & 0.000 & 42.568 & 0.000 \\
\hline vehicles & Necessary & 14.2 & 18.1 & 4.0 & 5.7 & 41.9 & & & & \\
\hline & Total & 24.1 & 52.1 & 17.3 & 6.5 & 100 & & & & \\
\hline Automated park- & Unnecessary & 16.1 & 15.6 & 5.4 & 5.7 & 42.8 & 54.665 & 0.000 & 55.201 & 0.000 \\
\hline ing system & Necessary & 7.9 & 36.5 & 11.9 & 0.8 & 57.2 & & & & \\
\hline & Total & 24.1 & 52.1 & 17.3 & 6.5 & 100 & & & & \\
\hline GPS based auto- & Unnecessary & 4.5 & 18.4 & 4.2 & 0.0 & 27.2 & 17.953 & 0.000 & 20.369 & 0.000 \\
\hline mated vehicle & Necessary & 19.5 & 33.7 & 13.0 & 6.5 & 72.8 & & & & \\
\hline locators & Total & 24.1 & 52.1 & 17.3 & 6.5 & 100 & & & & \\
\hline The intelligent & Unnecessary & 13.0 & 15.9 & 4.8 & 6.5 & 40.2 & 52.209 & 0.000 & 56.400 & 0.000 \\
\hline traffic manage- & Necessary & 11.0 & 36.3 & 12.5 & 0.0 & 59.8 & & & & \\
\hline ment centre & Total & 24.1 & 52.1 & 17.3 & 6.5 & 100 & & & & \\
\hline Intelligent traffic & Unnecessary & 5.7 & 12.2 & 7.4 & 0.0 & 25.2 & 18.019 & 0.000 & 19.459 & 0.000 \\
\hline information de- & Necessary & 18.4 & 39.9 & 9.9 & 6.5 & 74.8 & & & & \\
\hline vices & Total & 24.1 & 52.1 & 17.3 & 6.5 & 100 & & & & \\
\hline
\end{tabular}




\begin{tabular}{|c|c|c|c|c|c|c|c|c|c|c|}
\hline \multirow{3}{*}{$\begin{array}{l}\text { Automated travel } \\
\text { speed and time } \\
\text { locator }\end{array}$} & Unnecessary & 11.0 & 7.4 & 2.3 & 6.5 & 27.2 & \multirow[t]{3}{*}{98.535} & \multirow[t]{3}{*}{0.000} & \multirow[t]{3}{*}{94.451} & \multirow[t]{3}{*}{0.000} \\
\hline & Necessary & 13.0 & 44.8 & 15.0 & 0.0 & 72.8 & & & & \\
\hline & Total & 24.1 & 52.1 & 17.3 & 6.5 & 100 & & & & \\
\hline \multirow{3}{*}{$\begin{array}{l}\text { Automated vehi- } \\
\text { cle weight and } \\
\text { type detector }\end{array}$} & Unnecessary & 17.0 & 25.5 & 9.1 & 6.5 & 58.1 & \multirow[t]{3}{*}{29.204} & \multirow[t]{3}{*}{0.000} & \multirow[t]{3}{*}{34.071} & \multirow[t]{3}{*}{0.000} \\
\hline & Necessary & 7.1 & 26.6 & 8.2 & 0.0 & 41.9 & & & & \\
\hline & Total & 24.1 & 52.1 & 17.3 & 6.5 & 100 & & & & \\
\hline \multirow{3}{*}{$\begin{array}{ll}\text { E-ticketing and } \\
\text { automated fare } \\
\text { collection }\end{array}$} & Unnecessary & 14.4 & 24.4 & 7.4 & 4.5 & 50.7 & \multirow[t]{3}{*}{8.963} & \multirow[t]{3}{*}{0.029} & \multirow[t]{3}{*}{8.896} & \multirow[t]{3}{*}{0.030} \\
\hline & Necessary & 9.6 & 27.8 & 9.9 & 2.0 & 49.3 & & & & \\
\hline & Total & 24.1 & 52.1 & 17.3 & 6.5 & 100 & & & & \\
\hline
\end{tabular}

Authors' Fieldwork, 2019

\section{Conclusion and Recommendations}

The study has examined traffic congestion and Intelligent Transport System ITS in fast-growing Nigeria cities using Ibadan city as a reference point. It investigated the motorist profile and route characterization; identified factors aiding traffic congestion, the effectiveness of the existing traffic control measures and repeated approaches being used for its curtailment of traffic congestion in the city, the performance and disposition to the use of ITS devices in the study area. This has established that the existing mechanism in place as a congestion control mechanism remained ineffective as the strategies are being recycled for several years with the same results. It also underscores the rationale for a paradigm shift in the provision of better strategies for improving traffic congestion management in cities through the adoption and acceptance of the use of Intelligent Transport System ITS. This study affirmed that the persistent traffic congestion in Ibadan is being aggravated by ineffective control measures put in place aside from faulty junctions and intersections, unprofessional ethics and excesses of traffic officers, narrow road, haphazard on-street parking, neglect of pedestrian facilities, deplorable road, absence of road discipline, poor public transport, activities of motorcycles and tricycle operators as well as the indiscriminate location of traffic generating land use along the major roads/intersections.

Accordingly, road dualisation, human control, installation of the traffic signal, construction of flyover and underpass and other traditional and existing traffic control measures have not been able to manage traffic congestion to a tolerable level in the city; hence, the conclusion that they are inaccurate and inappropriately suitable to meet modern traffic congestion and its associated challenges in Nigeria cities. Therefore, the need to enhance intra-city movement and flow for efficient service delivery calls for improved measures such as the use of improved Intelligent Transport System.

This study concludes that traffic congestion and its accompanying challenges are increasingly worsening in Ibadan 42 years after the city hosted the first attention on transportation development in the country. As a result, the unlimited prospects which are domicile in smart technologies vis-à-vis ITS have to be holistically explored for improved traffic congestion management and flow movement in the city. Considering the various issues guiding smart transport, it is not an overstatement that Nigeria cities partially or wholly practice traffic congestion control based on discretion, political goal and for revenue drives, unlike the best practices as presented in the case of European cities where attention is been shifted to smart transport to minimize congestion and improved flow.

Therefore, smart transport components are recommended as a paradigm shift to traditional traffic congestion measures being used in Ibadan city and cities with similar traffic dilemma. Such measures include the use of Video Surveillance and Response (VSR) which involves continuous monitoring of key network locations to determine if traffic is moving or encountering congestion. Such monitoring is done with strategically located sensors or cameras, including different radar sensors, infrared and visible spectrum imaging and laser technology to observe flow interruptions and threats continuously. Also, informational signing such as variable messages which include electronic changeable message signs along the major roads and selected corridors to assist drivers regarding major congestion points on the road ahead is essential. These signs often give directions as to ways to avoid upcoming congestion points related to accidents, delay, congestion and the likes.

Also, the establishment of a Traffic Information Center (TIC) to be manned by personnel on 24 hours basis is extremely essential. This shall usually connect with other outside fixed and semi-fixed installations as well as mobile technologies from where traffic flows are being monitored and information disseminated to field units. Such TIC should be connected with VSR, CCTV, GPS, trackers, webcams, navigation system and many other technologies. As a result, strong political will is needed from the government by investing financially, legislatively, humanly and technologically in smart transport technologies. This will enhance transport development and management generally as a major pre-requisite for ICT enabling traffic management that will usher efficient service delivery. Finally, the nature of traffic flow in an area is usually a reflection of its pattern and structure of land uses. Therefore, exigency in the provision and enforcement of Intelligent Transport System ITS devices would be efficient in land use planning activities, spatial organisation and other urban metaphor including smart city, 
green city and liveable city if fully embraced and practised. As such, the need to properly integrate spatial planning using technological driven transport measures is unavoidably crucial to ensure free flow and sustainable intra-and-inter urban movements in the study area, and the nation at large, while taking into consideration, constraints to the adoption of ITS applications in Nigerian urban transport system such as epileptic electricity supply, non-availability of reliable traffic data and weak internet facility.

\section{REFERENCES}

[1] Adeniji, K., "Transport challenges in Nigeria in the next two decades", Monograph of Nigeria Institute of Social and Economic Research (NISER), vol.1, no.3, pp.40-67, 2000.

[2] Adesanya, A., "Analysis and management of transport sector performance and its intersectoral linkages", in lectures Delivered at the Training Programme on Sectoral Policy Analysis and Management, Ibadan, Nigeria, June 21-July 9, Ibadan: Nigeria Institute of Social and Economic Research (NISER), 2004.

[3] Akanmu, A. and Agboola, D., "Basic elements of traffic survey", Penthouse Publications, Ibadan, 2015.

[4] Akpoghomeh, O. S., "The terror of transport and the transportation of terror", an inaugural lecture University of Port Harcourt, Nigeria, University of Port Harcourt Press, Port Harcourt, 2012.

[5] Amiegbebhor, D., "Most significant causes of traffic congestion in Port Harcourt metropolis, Nigeria", International Journal of Academic Research and Reflection, vol.6, no.6, pp.8-17, 2018.

[6] Badejo, B. A., "Transportation: removing the clogs to Nigerian's development", Anchorage Press and Publishers, Lagos, 2011.

[7] European Commission, "Mobilizing intelligent transport systems for European cities", European Commission Staff Working Document, Brussels, 2013.

[8] Falola, T., "Ibadan warrior traditions and the anatomy of success", in lecture delivered at the 2009 Adegoke Adelabu Memorial Lectures at Mapo Hall, Ibadan, June 2009, University of Ibadan Press, Ibadan, 2009.

[9] Fourchard, L., "The case of Ibadan, Nigeria", University of Ibadan Press, Ibadan, 2000.

[10] Gbadamosi, K.T. and Akanmu, A.A., "Counterproductive nature of transportation externalities on the livability of Nigeria cities", in proceeding of the American Association of Geographer Annual Meeting, 3-7 April 2019, Washington D.C.: American Association of Geographer, 2019.

[11] Geenhuizen, M. V., "ICT application on the road to sustainable urban transport", European Transport, vol.41, pp.47-61, 2009.

[12] Harriet, T., Poku, K. and Emmanuel, A. K., “An assessment of traffic congestion and its effect on productivity in urban Ghana”, International Journal of Business and Social Science, vol.4, no.3, pp. 225-234, 2013.

[13] Jain, V., Sharma, A. and Subramanian, L., "Road traffic congestion in the developing world", in proceedings of DEV'12, March 11-12, ACM Publisher, Atlanta, GA, 2012.
[14] Lagos State Government Ministry of Economic Planning \& Budget, "The socio-economic costs of traffic congestion in Lagos", Economic Intelligence Unit Working Paper Series No 2: Lagos: Lagos State Government, 2013.

[15] Ministry of Works and Transport, "Draft report on Ibadan traffic control", Oyo State Government, Ibadan, 2001.

[16] Mitchell, W. J., "Smart city 2020”, unknown, 2012. Accessed at www.metropolismag.com/story.

[17] Nwakairu, J. N., Ohagwu, C. J. and Ani, A. O., "Possibilities of ICT as a means of poverty alleviation for rural dwellers in Nigeria", in proceedings of 3rd International Conference of WASAE. In: 9th International Conference of NIAE, January 25-29, Obafemi Awolowo University, Ile-Ife, Nigeria. Obafemi Awolowo University Press, pp. 408-413., 2009.

[18] Ogunsanya, A. A., "Makers and breakers of cities", an inaugural lecture of University of Ilorin, Nigeria. University of Ilorin Press, Ilorin, 2002.

[19] Ogunsesan, D. K., "Beautiful city, comfortable life: issues and challenges of Ibadan region, Nigeria", in lecture delivered at the Annual General Meeting, Investiture of New Executives and Award Night/Lecture of Ibadan Descendants Union, 26 February 2011, Ibadan Descendants Union, Ibadan, 2011.

[20] Ogunsesan, D. K. and Akanmu, A. A., "Hindrance to traffic movement in Ibadan metropolitan area: challenges and solutions", in lecture delivered at the Faculty of Environmental Studies Seminar Series of the Polytechnic, Ibadan, Nigeria, 19th May 2010, The Polytechnic of Ibadan Press, Saki, 2010.

[21] Ogunsesan, D. K., Akanmu, A. A. and Ogunsesan, A. S., "Appraising land-use and Ibadan traffic paralysis", Generalities Journal, vol.1, no.3, pp.85-93, 2012.

[22] Okoko, E., "Spatial Interaction: the quintessence of urban mobility", an inaugural lecture series 98 of Federal University of Technology, Akure, Nigeria, Federal University of Technology Akure Press, Akure, 2018.

[23] Onakomaiya, S. O., "Unsafe at any speed, toward road transportation survival", an Inaugural lecture of University of Ilorin, University of Ilorin Press, Ilorin, 1988.

[24] Orioke, J. M. A., "Traffic education and traffic flow in Ibadan city", in proceedings of Conference of the Nigerian Institute of Social and Economic Research at the University of Ibadan, 4-9 January, Nigerian Institute of Social and Economic Research (NISER), Ibadan, 1977.

[25] Oyesiku, O. O., "From womb to tomb", an inaugural lecture of Olabisi Onabanjo University, Ago-Iwoye, Nigeria, Olabisi Onabanjo University Press, Ago-Iwoye, 2002.

[26] Salisu, U.O., "State of transport administrative structure in Lagos, Ogun, and Oyo States, Nigeria", Journal of Spatial and Organizational Dynamics, vol.7, no.1, pp. 68-85, 2019.

[27] Shepelev, V., Aliukov, S., Nikolskaya, K., Das A., and Slobodin, I. "The use of multi-sensor video surveillance system to assess the capacity of the road network", Transport and Telecommunication, vol.21, no.1, pp.15-31, 2020. DOI 10.2478/ttj-2020-0002

[28] Shimizu, T., Shomura, Y., Masukawa, H. and Takeda, Y. Traffic management solutions for the social innovation business. Hitachi Review, vol.63, no.1, pp.52-56, 2014.

[29] Wen, L. Kenworthy, J., Guo, X. and Marinova, D., "Solving traffic congestion through street renaissance: a perspective from dense Asian cities", Urban Sci. vol.3, no.8, pp.1-21, 2019 DOI:10.3390/urbansci3010018. 